\title{
Restriction Fragment Length Polymorphism in Helicobacter pylori Associated with Gastric Cancer and Duodenal Ulcer
}

\author{
Koichi Kimura, ${ }^{1}$ Shunji Hayashi, ${ }^{1}$ Hiroshi Isogal, ${ }^{2}$ Emiko Isogal, ${ }^{3}$ Toshiro Sugiyama, ${ }^{4}$ Masahiro Asaka, \\ Tomonori Anbo, ${ }^{5}$ Akimichi Imamura, ${ }^{5}$ Takeshi Nishikawa, ${ }^{6}$ Toru Kubota' and Nobuhiro FusII' \\ 1 Department of Microbiology and ${ }^{2}$ Animal Experimentation Center, Sapporo Medical University, Sapporo 060-0061, Japan \\ ${ }^{3}$ Department of Preventive Dentistry School of Dentistry, Health Sciences University of Hokkaido, Hokkaido 061-0212, Japan \\ ${ }^{4}$ The 3rd Department of Internal Medicine, Hokkaido University School of Medicine, Hokkaido 047-0264, Japan \\ ${ }^{5}$ Division of Gastroenterology, Kousei Hospital, Sapporo 060, Japan \\ ${ }^{6}$ Department of Medical Science, Hokkaido University of Education, Sapporo 002-8075, Japan
}

Received for publication, December 1, 1997

More than $\mathbf{9 0 \%}$ of 75 clinical isolates of Helicobacter pylori strains had the vacuolating cytotoxin gene vacA as demonstrated by polymerase chain reaction (PCR). A PCR restriction fragment-length polymorphism (RFLP) analysis revealed various gene subtypes, and some of the RFLPs correlated significantly with gastric cancer or duodenal ulcer. These findings suggest that specific types of $\mathrm{H}$. pylori have factors that cause gastric cancer or duodenal ulcer.

Key words: Helicobacter pylori; RFLP; vacA; gastric cancer; duodenal ulcer

Helicobacter pylori infection might cause histological gastritis and contributes to peptic ulcer, gastric cancer and other gastrointestinal disorders (3). Patients infected with this bacterium can develop peptic ulcer or gastric cancer, but some people with $H$. pylori are asymptomatic. Although attempts to identify and characterize the pathogenic factors in this bacterium have been performed, no bacterial factors have yet been elucidated for these diseases (6-10). Attempts to classify H. pylori by their contribution to gastrointestinal disease have used genetic analysis of the bacterium, but the genetic diversity of $H$. pylori made such studies difficult except for duodenal ulcer $(1,8,16)$.

Vacuolating cytotoxin (VacA) causes vacuolization in various mammalian cells, and it might cause tissue injury (7). The association of vacA subtypes with duodenal ulcers has been previously reported (1), but the association of $v a c A$ subtypes with other gastrointestinal diseases has not been examined. The purpose of this study was to clarify the association of specific vacA genotypes with specific gastrointestinal diseases caused by $H$. pylori.

The $75 \mathrm{H}$. pylori strains used in this study were obtained by biopsy from patients with gastrointestinal diseases (August 1991-September 1994). Of the 75 strains, 13 were from patients with duodenal ulcer (mean \pm standard deviation, $54.3 \pm 12.1$ years), 22 with chronic gastritis (58.3 \pm 18.5 years), 20 with gastric ulcer ( $49.7 \pm$ 18.7 years) and 20 with gastric cancer $(68.1 \pm 15.7$ years). No patient received nonsteroidal anti-inflammatory drugs or antibiotics.

The biopsy specimens were excised sequentially from lesions or peripheral sites, followed by inoculation onto $H$. pylori-selective agar plates, which contained horse blood (10\%) and Skirrow-supplement (SR069E; OXOID, Hampshire, UK). The cultured bacteria were identified as $H$. pylori by Gram staining and oxidase, catalase and urease tests.

Chromosomal DNA was isolated using a QuickPrep DNA purification kit (Pharmacia, Uppsala, Sweden). Two oligonucleotide primer sets that characterized the vacA gene were used for PCR: (1) first primer set, 5'ATGGAAATACAACAAACACA-3' (1 nt to 20 nt of vacA) and 5'-TTAGAAACTATACCTCATTC-3' (3891 nt to 3872 nt of $v a c A$ ); and (2) second primer set, 5'TTTTACCTTTTTACACATTC-3' (-213 nt to $-194 \mathrm{nt}$ of $v a c A)$ and 5'-TGATGATAAGCTTGTGGTGTATGC-3' (3982 nt to $3959 \mathrm{nt}$ of vacA) $(5,11,12,14)$. The $v a c A$ gene is about $4 \mathrm{~kb}(1 \mathrm{nt}-3891 \mathrm{nt})$. Taq DNA polymerase (GIBCO BRL, New York, USA) was added after 2 min of preincubation at $94^{\circ} \mathrm{C}$, which was followed by 35 cycles, each of which was at $94^{\circ} \mathrm{C}$ for 45 sec and $65^{\circ} \mathrm{C}$ for $4 \mathrm{~min}$, with additional final incubation at $65^{\circ} \mathrm{C}$ for $10 \mathrm{~min}$.

The amplified DNA was subjected to BanI, XbaI or HpaII digestion by adding $10 \mu \mathrm{l}$ of the PCR product to $10 \mu \mathrm{l}$ of $2 \times$ concentrated reaction mixture, and the digested PCR product was analyzed by $2 \%$ agarose gel electrophoresis.

When the PCR for the first primer set was negative, the second primer set was used. By using the primer sets, 70 of $75(93.3 \%)$ of the clinical isolates were determined by PCR. Before digestion with restriction endonucleases, the PCR products were visualized as a 
Table 1. Profile of the PCR-RFLP of vacA of H. pylori from patients with gastric disorders

\begin{tabular}{lrrrrrrrr}
\hline \multirow{1}{*}{ Disease } & \multicolumn{10}{c}{ RFLP } & & & \\
\cline { 2 - 9 } & A & B & C & D & E & Other & — & Total \\
\hline Duodenal ulcer & 1 & 5 & 2 & 1 & 0 & 3 & 1 & 13 \\
Chronic gastritis & 2 & 2 & 3 & 2 & 0 & 12 & 1 & 22 \\
Gastric ulcer & 4 & 0 & 0 & 1 & 2 & 12 & 1 & 20 \\
Gastric cancer & 3 & 0 & 5 & 5 & 1 & 4 & 2 & 20 \\
\hline Total & 10 & 7 & 10 & 9 & 3 & 31 & 5 & 75 \\
\hline
\end{tabular}

$*$ : Not amplified.

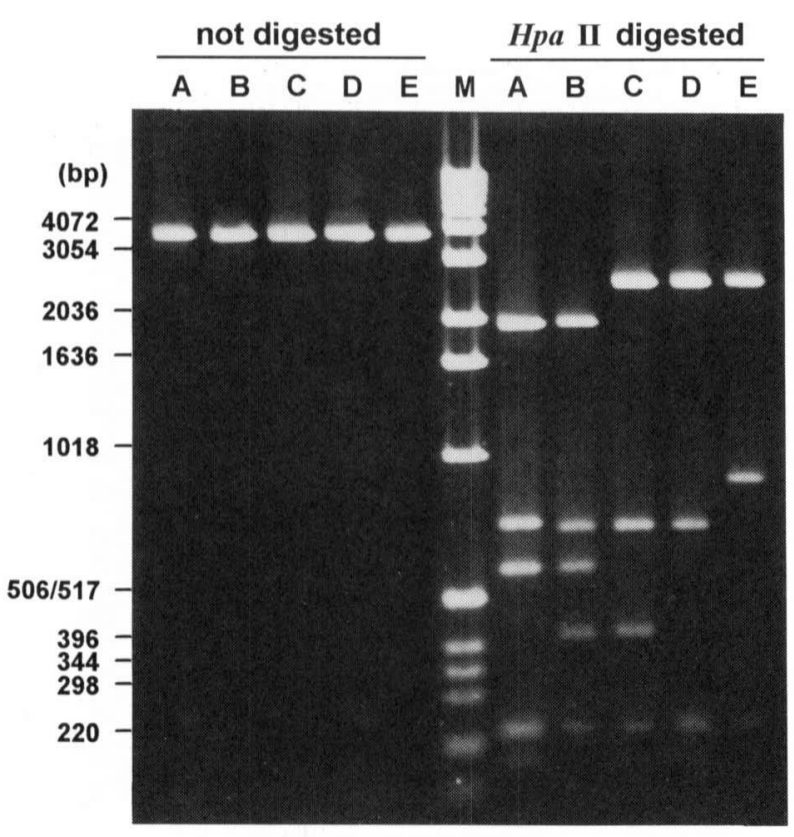

Fig. 1. Representative PCR-RFLP of vacA. A-E, PCR-RFLP; $\mathrm{M}$, molecular weight marker.

single band.

Although PCR-RFLP analysis with BanI or $\mathrm{XbaI}$ provided no significant classification, 39 strains of the 70 PCR-amplified products were classified into 5 groups (types A-E) by HpaII digestion (Fig. 1, Table 1). The remaining 31 strains were not characterized by PCRRFLP using HpaII digestion; therefore, they were not classified. The PCR-RFLP product of the HpaII-digested vacA sequences analyzed using the GenBank were not classified into these 5 groups (Fig. 2).

In type $\mathrm{B}$, the ratio of isolates from patients with duodenal ulcer was significantly higher than that of isolates from patients with chronic gastritis $(p<0.01)$ (Fig. $3)$. Type B was not isolated from patients with gastric carcinoma or gastric ulcer (Fig. 3, Table 1); therefore, it was suggested that type B was associated with duodenal ulcer. On the other hand, the strains obtained from

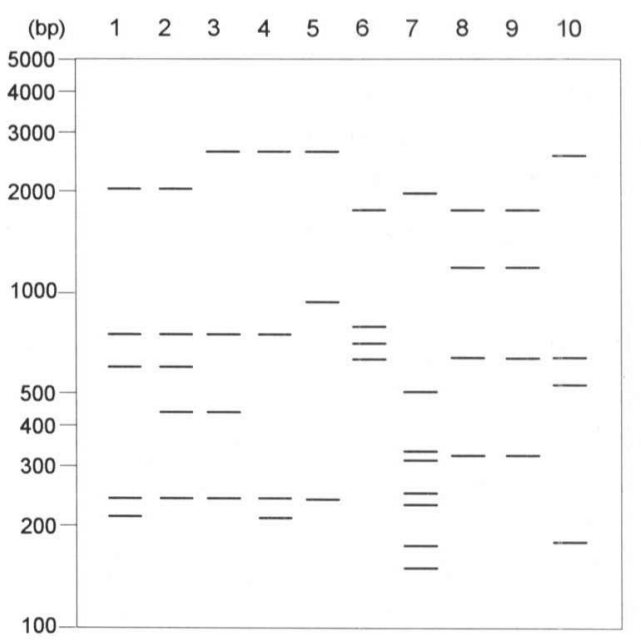

Fig. 2. Schematic representation of PCR-RFLP. Lanes 1-5, type A-E; lane 6, GenBank accession number U056765; lane 7, U29401 (non toxic); lane 8, U0714511; lane 9, S7249414; lane 10, Z2688312. PCR-RFLPs of lanes 6 to 10 were from previously known nucleotide sequences of vacA.

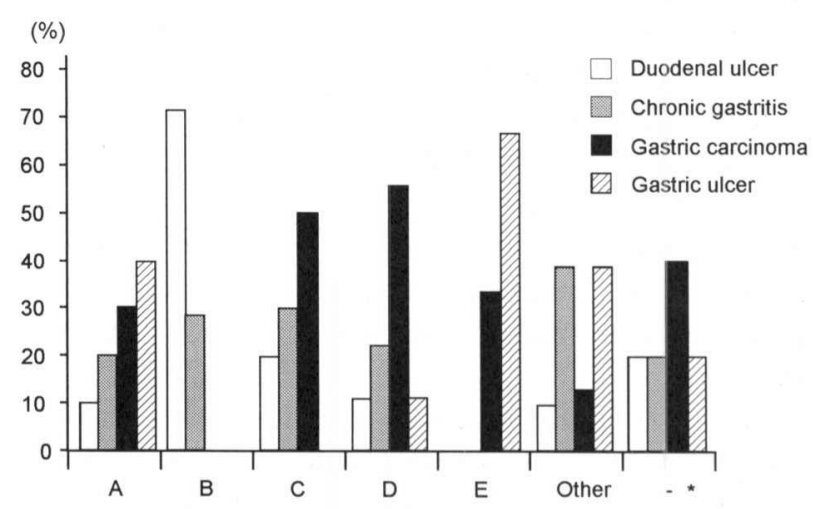

Fig. 3. Frequency distribution of the diseases that were positive for various vacA PCR-RFLPs. * : Not amplified.

patients with gastric cancer were predominantly of types $\mathrm{C}$ and D (Fig. 3, Table 1). The distribution of diseases that had the $\mathrm{C}$ strain was similar to that of diseases that had the D strain (Fig. 3). In addition, the RFLP of $\mathrm{Hpa}$ - 
II digestion was similar for the strains (Fig. 1); therefore, the $\mathrm{C}$ and $\mathrm{D}$ strains were combined and re-classified as cancer-related. The C/D strain occurred in patients with gastric cancer at a significantly higher rate as compared to the other strains $(p<0.01$, Table 1$)$. Strains A and E were not characteristic (Fig. 3).

Previous studies revealed marked variation in the genome of $H$. pylori strains $(4,13)$, which suggests that $H$. pylori is heterogeneous. Our results suggest a correlation between vacA genotype and disease phenotype, which indicates that there are disease-specific strains. Some factors for the diseases may occur only in specific H. pylori strains.

In the case of duodenal ulcer, our results suggest that type $\mathrm{B}$ is the associated strain. It has been suggested that $v a c A$ genotypes are associated with inflammation and/or epithelial damage in the stomach (2). Weel et al. demonstrated a correlation between $H$. pylori-mediated duodenal ulcer and the cytotoxin-associated genes (cagA) and vacA (15). Atheron et al. characterized three families of the $v a c A$ signal sequence (s1a, $\mathrm{s} 1 \mathrm{~b}$ and $\mathrm{s} 2$ ) and two families of the vacA middle region allele $(\mathrm{m} 1$ and $\mathrm{m} 2)(1,2)$. Ito et al. reported that most of the clinical isolates of $H$. pylori that occur in Japan were $\mathrm{s} 1 \mathrm{a} / \mathrm{m} 1$, and that the middle region of $v a c A$ in strains that occur in Japan were markedly homologous, with more than a $96 \%$ identity, but that most divergence occurs in the middle region (9). In this study, the vacA RFLP of 39 clinical isolates were classified into 5 groups. Specific strains of $H$. pylori may have accumulated in patients in Japan.

Although epidemiological studies indicated that $H$. pylori causes gastric cancer, the carcinogenic factor of H. pylori remains unknown $(3,10)$. H. pylori infection causes most histological gastritis, and atrophic gastritis is a risk factor for adenocarcinoma of the stomach. In this study, PCR-RFLP analysis of vacA demonstrated that the specific types of $H$. pylori, which were different from those abundant in gastric and duodenal ulcers, were predominant in patients with gastric cancer. This result does not necessarily indicate that $v a c A$ of type $\mathrm{C} / \mathrm{D}$ is responsible for gastric cancer since a gene really responsible for gastric cancer may exist near vacA and therefore link to specific types of $v a c A$. However, the result suggests that strains of carcinogenic $H$. pylori are different from strains that cause duodenal or gastric ulcers. The selection of $H$. pylori strains should be considered for the characterization of the carcinogenic factors of $H$. pylori.

Acknowledgments. This study was supported by grant No. 08770196 from the Ministry of Education of Japan and in part by the Grant-in-Aid for Cancer Research (8-14) from the Ministry of Health and Welfare.

\section{REFERENCES}

(1) Atherton JC, Cao P, Peek RM Jr, Tummuru MK, Blaser MJ and Cover TL. 1995. Mosaicism in vacuolating cytotoxin alleles of Helicobacter pylori. Association of specific $v a c A$ types with cytotoxin production and peptic ulceration. J Biol Chem 270: 17771-17777.

(2) Atherton JC, Peek RM Jr, Tham KT, Cover TL and Blaser ML. 1997. Clinical and pathological importance of heterogeneity in $v a c A$, the vacuolating cytotoxin gene of Helicobacter pylori. Gastroenterology 112: 92-99.

(3) Blaser MJ and Parsonnet J. 1994. Parasitism by the "slow" bacterium Helicobacter pylori leads to altered gastric homeostasis and neoplasia. J Clin Invest 94: 4-8.

(4) Bukanov NO and Berg DE. 1994. Ordered cosmid library and high-resolution physical-genetic map of Helicobacter pylori strain NCTC1 1638. Mol Microbiol 11: 509-523.

(5) Cover TL, Tummuru MK, Cao P, Thompson SA and Blaser MJ. 1994. Divergence of genetic sequences for the vacuolating cytotoxin among Helicobacter pylori strains. J Biol Chem 269: 10566-10573.

(6) Crabtree JE, Covacci A, Farmery SM, Xiang Z, Tompkins DS, Perry S, Lindley IJ and Rappuoli R. 1995. Helicobacter pylori induced interleukin-8 expression in gastric epithelial cells is associated with CagA positive phenotype. J Clin Pathol 48: 41-45.

(7) Ghiara P, Marchetti M, Blaser MJ, Tummuru MK, Cover TL, Segal ED, Tompkins LS and Rappuoli R. 1995. Role of the Helicobacter pylori virulence factors vacuolating cytotoxin, CagA, and urease in a mouse model of disease. Infect Immun 63: 4154-4160.

(8) Go MF and Graham DY. 1994. How does Helicobacter pylori cause duodenal ulcer disease: the bug, the host, or both? J Gastroenterol Hepatol 9 (Suppl 1): S8-S10.

(9) Ito Y, Azuma T, Ito S, Miyaji H, Hira M, Yamazaki Y, Sato F, Kato T, Kohli Y and Kuriyama M. 1997. Analysis and typing of the $\mathrm{VacA}$ gene from cagA-positive strains of Helicobacter pylori isolated in Japan. J Clin Microbiol 35: 1710-1714.

(10) Lynch DA and Axon AT. 1995. Helicobacter pylori, gastric cancer and gastric epithelial kinetics: a review. Eur $\mathbf{J}$ Gastroenterol Hepatol 7 (Suppl 1): S17-S23.

(11) Phadnis SH, Ilver D, Janzon L, Normark S and Westblom TU. 1994. Pathological significance and molecular characterization of the vacuolating toxin gene of Helicobacter pylori. Infect Immun 62: 1557-1565.

(12) Schmitt W and Haas R. 1994. Genetic analysis of the Helicobacter pylori vacuolating cytotoxin: structural similarities with the IgA protease type of exported protein. Mol Microbiol 12: 307-319.

(13) Taylor DE, Eaton M, Chang N and Salama SM. 1992. Construction of a Helicobacter pylori genome map and demonstration of diversity at the genome level. J Bacteriol 174: 6800-6806. 
(14) Telford JL, Ghiara P, Dell'Orco M, Comanducci M, Burroni D, Bugnoli M, Tecce MF, Censini S, Covacci A, Xiang Z, Papini E, Montecucco C, Parente L and Rappuoli R. 1994. Gene structure of the Helicobacter pylori cytotoxin and evidence of its key role in gastric disease. J Exp Med 179: 1653-1658.

(15) Weel JF, van der Hulst WM, Gerrit Y, Roorda PR, Feller M, Dankert J, Tytgat GNJ and van der Ende A. 1996. The interrelationship between cytotoxin-associated gene A, vacuolating cytotoxin, and Helicobacter pylori-related diseases. J Infect Dis 173: 1171-1175.

(16) Yoshimura HH, Evans DG and Graham DY. 1993. DNADNA hybridization demonstrates apparent genetic differences between Helicobacter pylori from patients with duodenal ulcer and asymptomatic gastritis. Dig Dis Sci 38: $1128-1131$. 